\title{
DESENVOLVIMENTO in vitro DE EMBRIÕES IMATUROS ORIUNDOS DE TANGERINEIRA 'PONCÃ' $x$ LARANJEIRA 'PERA' EM DIFERENTES FOTOPERÍODOS ${ }^{1}$
}

\author{
MOACIR PASQUAL ${ }^{2}$ \\ GUILHERME PEREIRA ALVES ${ }^{3}$ \\ LEONARDO FERREIRA DUTRA ${ }^{2}$ \\ EDVAN ALVES CHAGAS ${ }^{2}$ \\ LUCIENE DE OLIVEIRA RIBEIRO ${ }^{2}$
}

\begin{abstract}
RESUMO - Objetivou-se estudar a influência do fotoperíodo no cultivo in vitro de embriões imaturos oriundos do cruzamento entre tangerineira 'Poncã' e laranjeira 'Pera'. Os embriões foram extraídos de frutos com 3 - $4 \mathrm{~cm}$ de diâmetro e inoculados em meio MS, adicionado de $\mathrm{GA}_{3}$ e carvão ativado nas concentrações de 0,3 mg. $\mathrm{L}^{-1}$ e $1 \mathrm{mg} . \mathrm{L}^{-1}$, respectivamente, previamente autoclavado a $121^{\circ} \mathrm{C}$ por 20 minutos. Os tratamentos constaram dos seguintes fotoperíodos: 8, 10, 12, 14, 16, 18 e 24 horas de luz contínua, na intensidade luminosa de $43 \mu \mathrm{M} . \mathrm{m}^{-2} \cdot \mathrm{s}^{-1}$, a $27^{\circ} \mathrm{C}$, em estufas tipo B.O.D. O trata-
\end{abstract}

mento com 16 horas de luz contínua foi realizado em sala de crescimento em intensidade luminosa de 35 $\mu \mathrm{M} \cdot \mathrm{m}^{-2} \cdot \mathrm{s}^{-1}$. O experimento foi conduzido em delineamento inteiramente casualizado, com quatro repetições de três tubos de ensaio cada uma. Após 60 dias, melhores resultados para altura da parte aérea, número de folhas, peso da matéria fresca da parte aérea, comprimento das raízes e peso da matéria fresca das raízes foram obtidos com fotoperíodos de 8, 10, 12, 14, 18 e 24 horas. Fotoperíodo de 16 horas proporciona menor desenvolvimento de embriões imaturos.

TERMOS PARA INDEXAÇÃO: Citrus sinensis, Citrus reticulata, hibridação, cultura de embriões, fotoperíodo.

\section{In vitro DEVELOPMENT OF IMMATURE EMBRYOS FROM 'PONCÃ' MANDARIN $\times$ 'PERA' SWEET ORANGE IN DIFFERENT PHOTOPERIODS}

\begin{abstract}
It was aimed to study the influence of the photoperiod on in vitro culture of immature embryos from 'Poncã' mandarin and 'Pera' sweet orange fruits. The embryos were removed from 30-40$\mathrm{mm}$ wide fruits and inoculated on the MS medium, supplemented with $0.3 \mathrm{mg} \mathrm{L}^{-1} \mathrm{GA}_{3}$ and $1 \mathrm{mg} \mathrm{L}^{-1}$ activated charcoal, previously sterilized at $121^{\circ} \mathrm{C}$ for 20 minutes. The following photoperiods were evaluated: 8 , $10,12,14,16,18$, and 24 hours of continuous light in
\end{abstract}

$43 \mu \mathrm{M} . \mathrm{m}^{-2} \cdot \mathrm{s}^{-1}$ intensity, at $27^{\circ} \mathrm{C}$, in B.O.D chambers. The 16 hours continuous light was performed in growth room at $35 \mu \mathrm{M} \mathrm{m}^{-2} \mathrm{~s}^{-1}$. The statistical analysis used was entirely randomized, with four replications, each one constituted of three tubes. After 60 days, better results for plant height, number of leaves, above ground fresh matter weight, root length, and root fresh weight were obtained with $8,10,12,14,18$ e 24 hours photoperiod. The 16 hours rendered smaller immature embryos development.

INDEX TERMS: Citrus sinensis, Citrus reticulata, hybridization, embryo culture, photoperiod.

\section{INTRODUÇÃO}

A cultura de embriões é de grande importância no melhoramento dos citros, por proporcionar o resgate de embriões híbridos imaturos, oriun- dos de cruzamentos interespecíficos e intergenéricos. Incompatibilidades são, muitas vezes, encontradas em tais cruzamentos, o que resulta em sementes com embriões abortivos (Hu \& Ferreira, 1998).

1. Apoio Financeiro da FAPEMIG.

2. Departamento de Agricultura, Laboratório de Cultura de Tecidos - UNIVERSIDADE FEDERAL DE LAVRAS/

UFLA - Caixa Postal 37 - 37200-000 - Lavras, MG. mpasqual@ufla.br.

3. Faculdade de Ciências Agrárias do Pará, Caixa Postal 917 - 66077-530 - Belém, PA. 
A poliembrionia generalizada entre as espécies de Citrus resulta normalmente em elevada taxa de aborto do embrião zigótico, devido à competição exercida sobre ele pelos embriões nucelares, geralmente mais vigorosos (Soost \& Cameron, 1975). Entretanto, esses embriões podem ser resgatados via cultivo in vitro em meio de cultura adequado (Sharma et al., 1996). Trabalhos têm sido realizados objetivando elucidar os efeitos dos diversos fatores no cultivo in vitro de embriões de citros (Ribeiro et al., 1997, 1998, 1999, 2000).

O crescimento das plantas é controlado por fatores genéticos e ambientais, os quais atuam conjuntamente mediante processos fisiológicos. A luz, segundo Economou \& Read (1987), interfere nos processos fotossintéticos e de fotomorfogênese, por meio da qualidade (comprimento de onda), quantidade (intensidade luminosa ou fluxo de fótons) e duração (fotoperíodo).

O fotoperíodo afeta os níveis hormonais endógenos das plantas e, conseqüentemente, modifica o seu crescimento, atuando diferentemente para cada espécie (Salisbury \& Ross, 1991). Para haver efeito fotoperiódico, a quantidade de energia luminosa total necessária é insignificante, pois, na realidade, a duração do período do escuro é que atua como agente controlador de diversos processos fisiológicos das plantas (Bolonhezi, 1991; Salisbury \& Ross, 1991; Thomas \& Vince-Prue, 1997).

Não se dispõe de informações sobre o efeito do fotoperíodo no desenvolvimento de embriões imaturos de citros. O que se tem é a recomendação de que, após a inoculação, os embriões devam permanecer por 48 horas no escuro e, posteriormente, em sala de crescimento à temperatura de $27 \pm 1^{\circ} \mathrm{C}$, com fotoperíodo de 16 horas diárias em $35 \mu \mathrm{Mm}^{-2} . \mathrm{s}^{-1}$ de intensidade luminosa. Entretanto, vários trabalhos foram desenvolvidos testando-se o efeito do fotoperíodo em diferentes espécies, como batata-doce (Bonsi et al., 1992; McDavid \& Alamu, 1980; Figueiredo, 1995), dália (Moser \& Hess, 1968), macieira e amoreirapreta (Souza, 1995). Estudos com plântulas e segmentos caulinares de algumas espécies apresentaram resultados conflitantes com relação à influência de diferentes fotoperíodos (Delgado et al., 1996), o que tem sido atribuído ao fato de que a luz é um entre vários fatores que interferem no crescimento e desenvolvimento vegetal.

Objetivou-se testar a influência de fotoperíodo sobre o cultivo in vitro de embriões híbridos oriundos do cruzamento entre tangerineira 'Poncã' e laranjeira 'Pera'.

\section{MATERIAL E MÉTODOS}

Sementes de frutos com $3-4 \mathrm{~cm}$ de diâmetro de tangerineira 'Poncã' (Citrus reticulata Blanco) x laranjeira 'Pera' (Citrus sinensis (L.) Osbeck) foram removidas e tratadas com álcool a $70 \%$ por cinco minutos e hipoclorito de sódio a $2 \%$ por 20 minutos, sendo, posteriormente, lavadas três vezes em água bidestilada e autoclavada.

Com auxílio de microscópio estereoscópico, bisturi e pinça, os tegumentos das sementes foram separados longitudinalmente pela região oposta à micrópila, tomando-se o cuidado de não provocar danos aos embriões.

Todos os embriões, independentemente dos estádios em que se encontravam, foram excisados e inoculados individualmente em tubos de ensaio contendo $15 \mathrm{~mL}$ do meio MS (Murashige \& Skoog, 1962), acrescido de 0,3 mg.L $L^{-1}$ de $\mathrm{GA}_{3}$ (ácido giberélico) e de 1 g.L $\mathrm{L}^{-1}$ de carvão ativado e acondicionados em estufas tipo B.O.D., sob temperatura constante de $27{ }^{\circ} \mathrm{C}$ e intensidade luminosa de 43 $\mu \mathrm{M} . \mathrm{m}^{-2} \cdot \mathrm{s}^{-1}$, e os tratamentos constaram dos seguintes fotoperíodos: $8,10,12,14,16,18$ e 24 horas de luz contínua. O tratamento com 16 horas de luz contínua foi realizado em sala de crescimento em intensidade luminosa de 35 $\mu \mathrm{M} \cdot \mathrm{m}^{-2} \cdot \mathrm{s}^{-1}$. O experimento foi conduzido em delineamento inteiramente casualizado, com quatro repetições, cada uma constituída por três tubos de ensaio.

Após 60 dias, as plântulas foram avaliadas com base na altura da parte aérea, número de folhas, peso da matéria fresca da parte aérea, comprimento das raízes e peso da matéria fresca das raízes.

\section{RESULTADOS E DISCUSSÃO}

Houve efeito significativo de fotoperíodo para todas as características analisadas, exceto para número de folhas (Tabela 1).

Embriões expostos à luz por apenas 8 horas de luz diárias apresentaram plântulas com maior altura da parte aérea (Figura 1), apesar de não terem sido identificadas diferenças significativas em relação aos tratamentos com 10 , $12,14,18$ e 24 horas de exposição à luz.

Não houve diferença significativa entre os tratamentos para número de folhas (Tabela 1). Verificouse, no entanto, tendência de maior número de folhas no tratamento com 24 horas de luz contínua (Figura 2).

Os melhores fotoperíodos para peso de matéria fresca da parte aérea foram 10,12 e 14 horas de luz contínua, não diferindo dos tratamentos com 8, 18 e 24 horas (Figura 3). De maneira semelhante ao resultado obtido na altura da parte aérea, o tratamento com 16 horas de luz contínua foi inferior aos demais. 
TABELA 1 - Análise de variância para altura da parte aérea (APA), número de folhas (NF), peso da matéria fresca da parte aérea (PMFPA), comprimento de raízes (CR) e peso da matéria fresca das raízes (PMFR) de plântulas oriundas de embriões cultivados em diversos fotoperíodos. UFLA, Lavras-MG, 2002.

\begin{tabular}{ccccccc}
\hline Causa de & & \multicolumn{6}{c}{ Quadrado Médio } \\
\cline { 3 - 7 } Variação & G.L. & APA & NF & PMFPA & CR & PMFR \\
\hline Tratamento & 6 & $0,3091^{* *}$ & 1,5942 & $90,8199^{* *}$ & $2,1374^{* *}$ & $10,3724^{* *}$ \\
Resíduo & 21 & 0,0800 & 1,1662 & 18,9663 & 6,3087 & 0,9857 \\
\hline C.V $(\%)$ & & 16,6 & 29,5 & 13,9 & 24,4 & 18,0 \\
\hline
\end{tabular}

**Significativo a $1 \%$ de probabilidade.

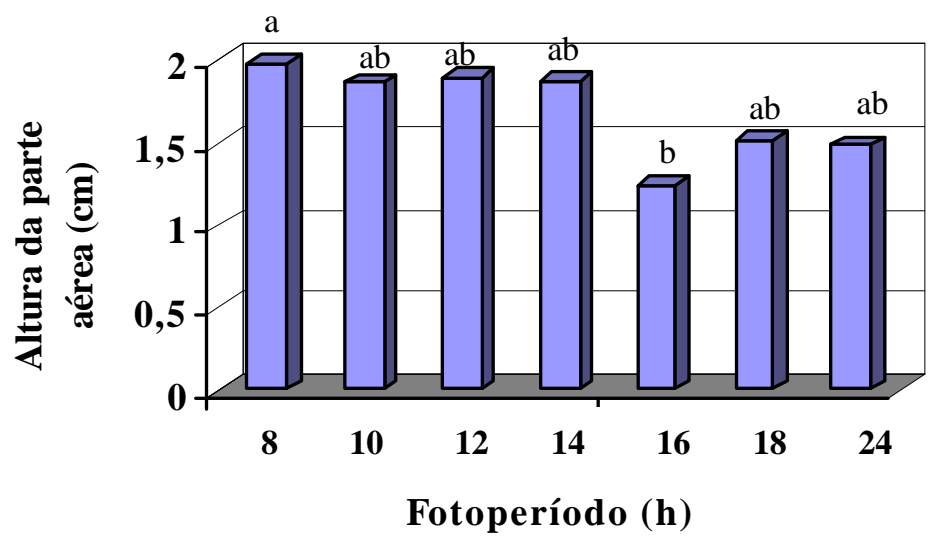

FIGURA 1 - Altura da parte aérea de plântulas oriundas de embriões cultivados em diversos fotoperíodos. UFLA, Lavras-MG, 2002.

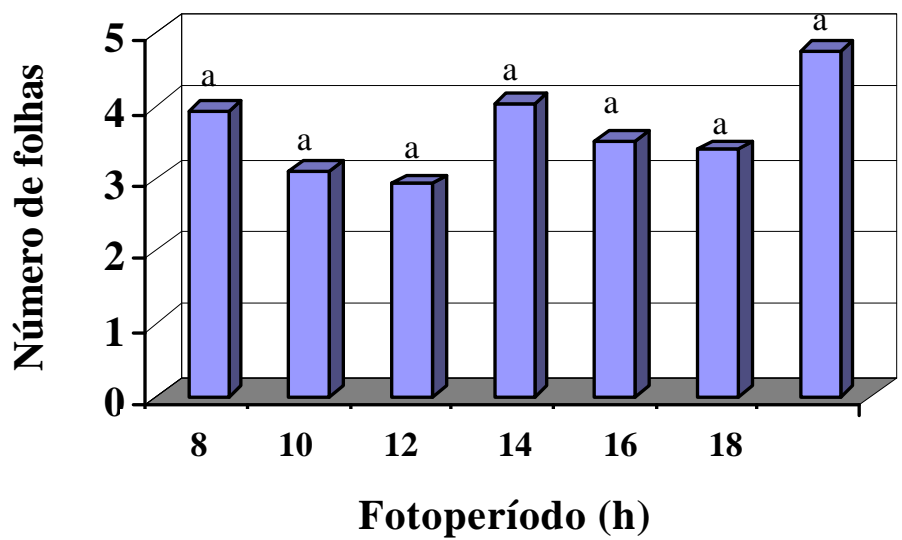

FIGURA 2 - Número de folhas de plântulas oriundas de embriões cultivados em diversos fotoperíodos. UFLA, Lavras-MG, 2002. 
Os maiores comprimentos de raiz foram obtidos com 14 e 24 horas de luz contínua (Figura 4).

Por meio dessa resposta, verifica-se que a eficiência do crescimento pode estar relacionada à habilidade de adaptação das plantas às condições de luz do ambiente in vitro. A intensidade de luz (Ferreira \& $\mathrm{Hu}, 1989)$ ou a qualidade dessa $(\mathrm{Hu}$ \& Ferreira, 1989) podem também influenciar o desenvolvimento embrionário. Os embriões rudimentares no estádio cordiforme em numerosas espécies de Ilex são sensíveis à luz, quando excisados e cultivados in vitro (Hu, 1976; Ferreira \& Hu, 1984).
A sensibilidade desses embriões desaparece após 4 dias de incubação no escuro, e eles crescem até a maturidade na luz. Dessa forma, depois de ser iniciado, o processo fisiológico não pode ser mais revertido $(\mathrm{Hu} \&$ Ferreira, 1998), o que notadamente aconteceu em relação ao tratamento 24 horas de luz contínua, em que os embriões mostraram total adaptação a esse fotoperíodo.

Os maiores pesos de peso da matéria fresca das raízes foram obtidos com 14 e 24 horas de luz contínua, porém sem diferença em relação a 8,10 e 18 horas (Figura 5). Novamente o pior resultado foi verificado com a utilização de fotoperíodo com 16 horas de luz contínua.

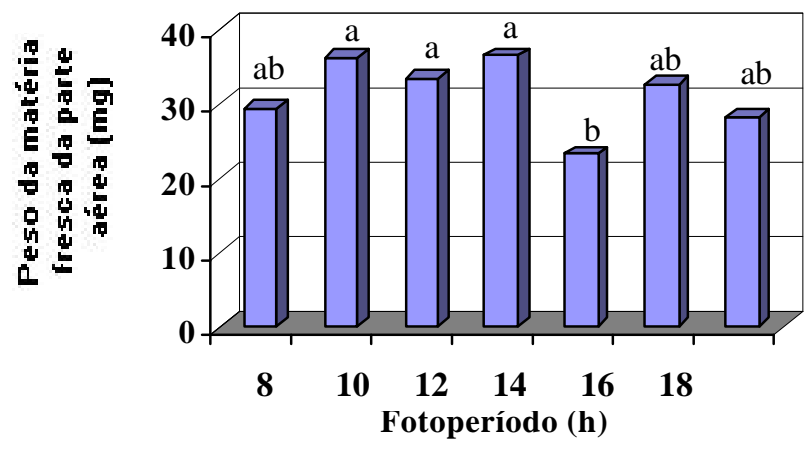

FIGURA 3 - Peso da matéria fresca da parte aérea de plântulas oriundas de embriões cultivados em diversos fotoperíodos. UFLA, Lavras-MG, 2002.

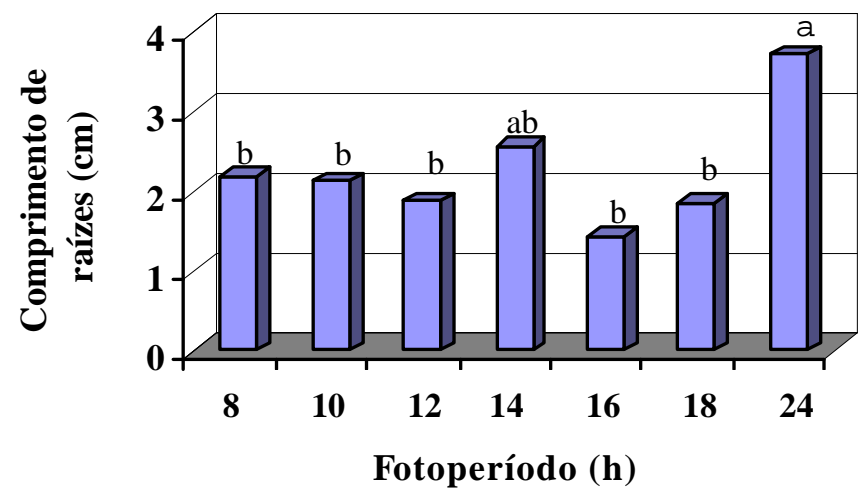

FIGURA 4 - Comprimento de raízes de plântulas oriundas de embriões cultivados em diversos fotoperíodos. UFLA, Lavras-MG, 2002. 


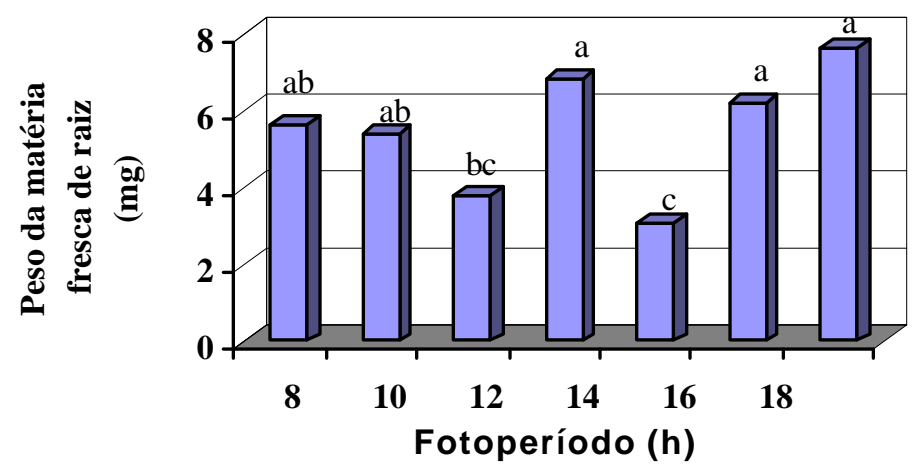

FIGURA 5 - Peso da matéria fresca das raízes $(\mathrm{mg})$ de plântulas oriundas de embriões cultivados em diversos fotoperíodos. UFLA, Lavras-MG, 2002.

É interessante observar que embriões cultivados sob regime de 16 horas de luz contínua, condição padrão para a maioria dos cultivos realizados em laboratório, proporcionou o pior resultado em termos de altura da parte aérea de plântulas, peso da matéria fresca da parte, comprimento e peso da matéria fresca de raízes. Esse resultado pode estar relacionado ao fato de que na sala de crescimento, onde foram mantidos os embriões sob 16 horas de luz contínua, há maior desuniformidade com relação às condições de temperatura e luz. Além disso, nessas condições, a quantidade de radiação fotossinteticamente ativa é sensivelmente menor $\left(32 \mu \mathrm{M} \cdot \mathrm{m}^{-2} \cdot \mathrm{s}^{-1}\right)$ do que aquela observada na estufa tipo B.O.D. $\left(43 \mu \mathrm{M} \cdot \mathrm{m}^{-2} \cdot \mathrm{s}^{-1}\right)$.

\section{CONCLUSÃO}

Nas condições em que o experimento foi conduzido, pode-se concluir que:

a) Fotoperíodos com 8, 10, 12, 14, 18 e 24 horas proporcionam melhor desenvolvimento de embriões imaturos oriundos do cruzamento laranjeira 'Pera' $\mathrm{x}$ tangerineira 'Poncã;

b) Fotoperíodo com 16 horas de luz contínua induz menor desenvolvimento de embriões imaturos.

\section{REFERÊNCIAS BIBLIOGRÁFICAS}

BOLONHEZI, A. C. Influência do fotoperíodo sobre o desenvolvimento da planta e produção de raízes tuberosas de mandioca (Manihot esculenta Crantz). 1991. 228 f. Tese (Doutorado em Fitotecnia) - Escola Superior de Agricultura Luiz de Queirós, Piracicaba.
BONSI, C. K.; LORETAN, P. A.; HILL, W. A.; MORTLEY, D. G. Response of sweet potato to continuous light. HortScience, Alexandria, v. 27, n. 5, p. 471, May 1992.

DELGADO, G. E.; SALATINO, M. L.; HANDRO, W. Enhancement of anthocyanin and anthocyanidin synthesis by light, growth regulators and sucrose in in vitro plants of sweet potato. Revista Brasileira de Fisiologia Vegetal, Brasília, v. 8, n. 2, p. 111-115, 1996.

ECONOMOU, A. S.; READ, P. E. Light treatments to improve efficiency of in vitro propagation systems. HortScience, Alexandria, v. 22, n. 5, p. 751-754, Oct. 1987.

FERREIRA, A. G.; HU, C. Y. Influência da luz na embriogênese tardia de Ilex: cultura in vitro. In: CONGRESSO NACIONAL DE BOTÂNICA, 34., 1984, Porto Alegre. Anais... Porto Alegre: SBB, 1984. p. 441-449.

FERREIRA, A. G.; HU, C. Y. Light-mediated inhibition of in vitro late embryogeny of Ilex. Journal of American Society for Horticultural Science, Alexandria, v. 114, p. 819-823, 1989.

FIGUEIREDO, S. A. Influência de reguladores de crescimento e fotoperíodo no crescimento secundário de raízes de Ipomoea batatas (L.) Lam. Brazlândia Branca em condições in vitro. 1995. 78 f. Dissertação (Mestrado em Fitotecnia) - Universidade Federal de Lavras, Lavras. 
HU, C. Y. Light-mediated inhibition of in vitro development of rudimentary embryos of Ilex opacs. American Journal of Botany, Columbus, v. 63, p. 651-656, 1976.

HU, C. Y.; FERREIRA, A. G. In vitro embriology of Ilex. In: PARÉ, J.; BUGNICOURT, M. Some aspects and actual orientations in plant embryology. Amiens: University of Picardie, 1989. p. 76-90.

HU, C. Y.; FERREIRA, A. G. Cultura de embriões. In: TORRES, A. C.; CALDAS, L. S.; BUSO, J. A. (Eds.). Cultura de tecidos e transformações genéticas de plantas. Brasília: EMBRAPA-CBAB, 1998. p. 371394.

MCDAVID, C. P.; ALAMU, S. Effect of day lenght on the growth and development of whole plants and rooted leaves of sweet potato (Ipomoea batatas). Tropical Agriculture, Trindad, v. 57, n. 2, p. 113-119, Apr. 1980.

MURASHIGE, T.; SKOOG, F. A revised medium for rapid growth and biossays with tabacco tissue culture. Physiologia Plantarum, Copenhagen, v. 15, p. 473497, 1962.

MOSER, B. C.; HESS, C. E. The physiology of tuberous root development in dahlia. Journal American Society Horticultural Science, Alexandria, v. 33, n. 6, p. 595-603, Nov. 1968.

RIBEIRO, V. G.; PASQUAL, M.; RAMOS, J. D. Influência do $\mathrm{pH}$ e do ágar sobre o cultivo in vitro de embriões de laranjeira 'Pera'. Pesquisa Agropecuária Brasileira, Brasília, v. 32, p. 1147-1152, 1997.
RIBEIRO, V. G.; PASQUAL, M.; RAMOS, J. D. Cultivo in vitro de embriões de laranja 'Pera': concentrações do meio MS e sacarose. Pesquisa Agropecuária Brasileira, Brasília, v. 22, p. 429-434, 1998.

RIBEIRO, V. G.; PASQUAL, M.; RAMOS, J. D. Influência do ágar e do $\mathrm{pH}$ sobre o cultivo in vitro de embriões de laranja 'Natal'. Revista Ceres, Viçosa, v. 46, p. $587-595,1999$.

RIBEIRO, V. G.; SANÁBIO, D.; SOUZA, C. N. de. Efeitos de ácido giberélico e carvão ativado no cultivo in vitro de Citrus limonia Osbeck x Poncirus trifoliata (L.) Raf. Pesquisa Agropecuária Brasileira, Brasília, v. 35, p. 27-30, 2000.

SALISBURY, F. B.; ROSS, C. W. Plant physiology. 4. ed. Belmont: Wadsworth, 1991. 682 p.

SHARMA, D. R.; KAUR, R.; KUMAR, K. Embryo rescue in plants: a review. Euphytica, Wageningen, $v$. 89, p. 325-37, 1996.

SOOST, R. K.; CAMERON, J. W. Citrus. In: JANICK, J.; MOORE, J. N. (Eds.). Advances in fruit breeding. West Lafayette: Purdue University, 1975. p. 507-40.

SOUZA, A. S. Efeitos da sacarose e do fotoperíodo na propagação in vitro da cv. Ébano de amora-preta e dos porta-enxertos de macieira 'MM.111' e pereira Pyrus calleryana Deene. 1995. 36 f. Dissertação (Mestrado em Fitotecnia) - Universidade Federal de Lavras, Lavras.

THOMAS, B.; VINCE-PRUE, D. Photoperiodism in plants. 2. ed. San Diego: Academic, 1997. 428 p. 